\title{
The Effects of Pertussis Toxin-Treatment on Integrated Vasoactive Response of Vascular System in Spontaneously Hypertensive Rats
}

\author{
S. ČAČÁNYIOVÁ, F. KRISTEK, J. KUNEŠ ${ }^{1}$, J. ZICHA ${ }^{1}$ \\ Institute of Normal and Pathological Physiology and Centrum of Excellence for Cardiovascular \\ Research, Slovak Academy of Sciences, Bratislava, Slovak Republic, ${ }^{1}$ CRC and Institute of \\ Physiology, Academy of Sciences of the Czech Republic, Prague, Czech Republic
}

Received December 7, 2007

Accepted January 3, 2008

\begin{abstract}
Summary
We investigated the effect of pertussis toxin (PTX) on hypotensive response induced by acetylcholine (ACh) and bradykinin (BK) and on noradrenaline (NA)-induced pressor response in spontaneously hypertensive rats (SHR). Fifteenweek-old Wistar rats and age-matched SHR were used. Half of SHR received PTX $(10 \mu \mathrm{g} / \mathrm{kg} / \mathrm{i} . v$. $)$ and the experiments were performed $48 \mathrm{~h}$ later. After the anesthesia the right carotid artery was cannulated in order to record blood pressure (BP). The hypotensive response to ACh was enhanced in SHR compared to Wistar rats. After pretreatment of SHR with PTX the hypotensive response to ACh was reduced compared to untreated SHR and it was also diminished in comparison to Wistar rats. Similarly, the hypotensive response to BK was also decreased after PTX pretreatment. The pressor response to NA was increased in SHR compared to Wistar rats. NA-induced pressor response was considerably decreased after PTX pretreatment compared to untreated SHR. In conclusion, the enhancement of hypotensive and pressor responses in SHR was abolished after PTX pretreatment. Our results suggested that the activation of PTXsensitive inhibitory $G_{i}$ proteins is involved in the regulation of integrated vasoactive responses in SHR and PTX pretreatment could be effectively used for modification of BP regulation in this type of experimental hypertension.
\end{abstract}

\section{Key words}

SHR - Pertussis toxin - Blood pressure - Noradrenaline • Acetylcholine $\bullet$ Bradykinin $\bullet$ Vasoactive responses

\section{Corresponding author}

Soňa Čačányiová, Institute of Normal and Pathological Physiology, Slovak Academy of Sciences, Sienkiewiczova 1, 813 71 Bratislava, Slovak Republic.

E-mail: Sona.cacanyiova@savba.sk
Pertussis toxin (PTX) inactivates inhibitory G proteins $\left(G_{i}\right.$ proteins) which modulate a variety of intracellular events (Casey and Gilman 1988). Guanine nucleotide $\mathrm{G}_{\mathrm{i}}$ protein couples receptors in an inhibitory mode to adenylate cyclase activity leading to a suppression of cAMP production. An enhanced expression of $G_{i}$ proteins was found in spontaneously hypertensive rats (SHR) in which the inactivation of Gi protein overexpression by PTX attenuated the development of high blood pressure (Li and AnandSrivastava 2002). Recent studies of Pintérová et al. (2006, 2007) indicated that PTX treatment caused a greater BP reduction in SHR than in WKY rats. This BP decrease was due to a major attenuation of sympathetic vasoconstriction as a consequence of largely diminished responsiveness of resistance arteries to endogenous (or exogenous) noradrenaline.

The aim of our study was to investigate the effects of PTX pretreatment on the hypotensive response induced by acetylcholine (ACh) or bradykinin (BK) and on noradrenaline (NA)-induced pressor response in SHR.

The experiments were performed in the 6 adult male 15-week-old Wistar rats (used as controls) and 12 age-matched SHR. Half of hypertensive rats received an i.v. injection of PTX $(10 \mu \mathrm{g} / \mathrm{kg} / \mathrm{i} . \mathrm{v}$. $)$ and the experiments were performed $48 \mathrm{~h}$ later. The animals in each group were anesthetized i.p. with ketamine and xylazine $(0.25$ and $0.1 \mathrm{ml} / 100 \mathrm{~g}$ body weight $)$ and the right carotid artery was cannulated for blood pressure recording. After BP stabilization during next $15 \mathrm{~min}$, ACh $(10 \mu \mathrm{g})$, BK $(10 \mu \mathrm{g})$ or NA $(0.1 \mu \mathrm{g}$ and $1.0 \mu \mathrm{g})$, 


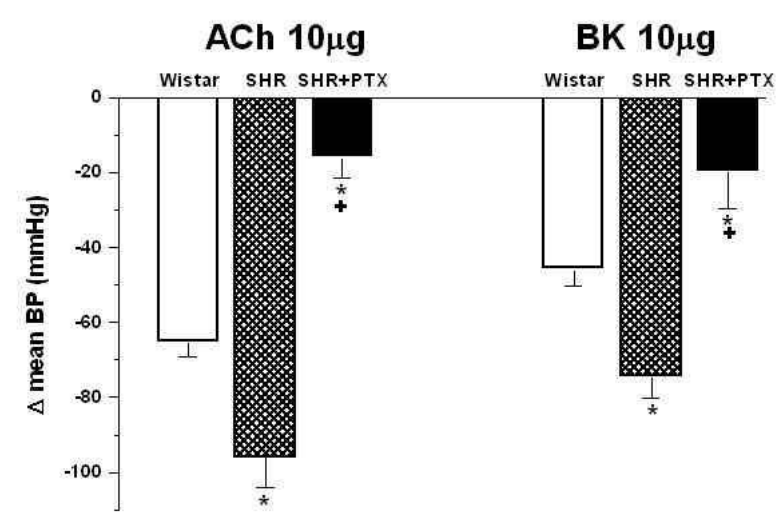

Fig. 1. Decrease of mean arterial pressure elicited by acetylcholine (ACh) or bradykinin (BK) injection in Wistar rats, untreated SHR and in SHR treated with pertussis toxin $(\mathrm{SHR}+\mathrm{PTX})$. Values are mean \pm S.E.M. $* \mathrm{p}<0.01$ vs Wistar rats, ${ }^{+} p<0.01$ vs SHR

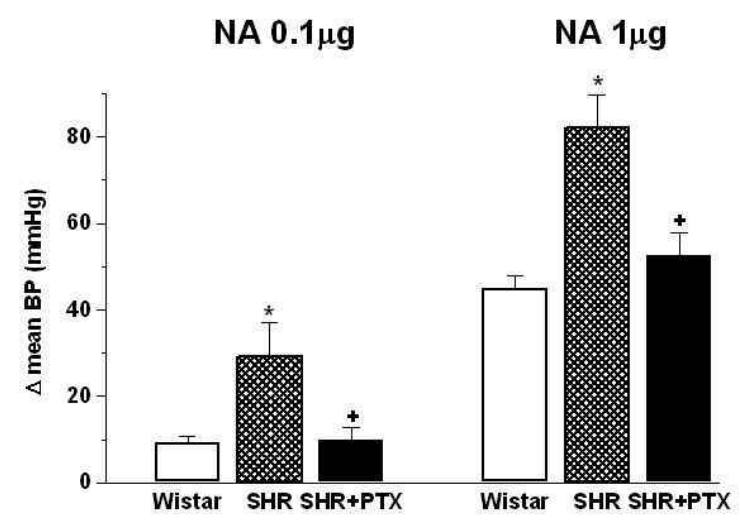

Fig. 2. Increase of mean arterial pressure after noradrenaline (NA) injection in Wistar rats, untreated SHR and in SHR treated with pertussis toxin (SHR+PTX). Values are mean \pm S.E.M. ${ }^{*} p<0.01$ vs Wistar rats, ${ }^{+} p<0.01$ vs SHR

each dissolved in $0.1 \mathrm{ml}$ Krebs solution, were administered as bolus injections into the jugular vein within $10 \mathrm{~s}$.

Baseline values of mean arterial pressure were higher in SHR $(160.85 \pm 9.95 \mathrm{~mm} \mathrm{Hg}$; $<<0.01)$ compared to Wistar rats $(128.62 \pm 3.13 \mathrm{~mm} \mathrm{Hg})$, whereas $\mathrm{BP}$ was substantially decreased in SHR treated with PTX $(84.74 \pm 6.20 \mathrm{mmHg} ; \mathrm{p}<0.01)$ below the control values. The hypotensive response to ACh was increased in SHR compared to normotensive Wistar rats $(\mathrm{p}<0.01)$ and the same was true for BP reduction occurring after BK injection. It should be noted that after the pretreatment of SHR with PTX the hypotensive responses to ACh or BK were decreased compared to both untreated SHR $(\mathrm{p}<0.01)$ and Wistar rats $(\mathrm{p}<0.01)$ (Fig.1). The pressor response to NA was increased in SHR compared to
Wistar rats $(\mathrm{p}<0.01)$. PTX pretreatment of SHR diminished NA-induced pressor response compared to untreated SHR $(p<0.01)$. Their pressor response became comparable with that observed in control Wistar rats (Fig. 2).

The treatment with PTX attenuated the pressor response to noradrenaline compared to untreated SHR and returned it to the level seen in normotensive Wistar rats. Our results suggest that vasoconstriction induced by noradrenaline is mediated by a PTX-sensitive $\mathrm{G}_{\mathrm{i}}$-proteinconnected intracellular pathway in smooth muscle cells of resistance arteries. This is in a good agreement with other studies done on isolated arteries (Abebe et al. 1995, Spitzbarth-Régriny et al. 2000). Both human essential hypertension and genetic hypertension of the rats are characterized by an enhanced sympathoadrenergic activity and increased adrenergic vasoconstriction. The enhanced $\mathrm{G}_{\mathrm{i}}$ protein expression in genetic hypertension (Li and Anand-Srivastava 2002) and the effects of the pretreatment with PTX (this study, Pintérová et al. 2006, 2007) suggest that Gi proteins might be potential targets of future antihypertensive drugs.

The endothelium-dependent vasodilation (elicited in our study by acetylcholine or bradykinin) was sensitive to the effects of pertussis toxin because the hypotensive responses to both agonists were significantly decreased in hypertensive rats treated with PTX compared to untreated SHR. This is in contrast to earlier finding (Flavahan et al. 1989) that PTX did not inhibit the relaxations mediated by nitric oxide. The question is open whether the decreased nitric oxide-mediated response is associated with the impairment of $G_{i}$ proteins by PTX and/or whether it reflects the compensatory mechanism as a response to a long-term blood pressure reduction due to significant decrease of peripheral resistance in PTX-treated rats. Nevertheless, it remains to determine which step in the activation of endothelial receptors by acetylcholine or bradykin is dependent on PTX-sensitive $\mathrm{G}_{\mathrm{i}}$-proteins.

\section{Conflict of Interest}

There is no conflict of interest.

\section{Acknowledgement}

This study was supported by grants VEGA 2/6139/27 and 1M051 (Cardiovascular Research Centre, Prague). The authors thank L'. Kosnáčová for technical help and Y. Hanáčková for help with housing the animals. 


\section{References}

ABEBE W, EDWARDS JD, AGRAWAL DK: G-proteins in rat blood vessels. II. Assessment of functional involvement. Gen Pharmacol 26: 75-83, 1995.

CASEY PJ, GILMAN AG: G-protein involvement in receptor coupling. J Biol Chem 263: 2577-2580, 1988.

FLAVAHAN NA, SHIMOKAWA H, VANHOUTTE PM: Pertussis toxin inhibits endothelium-dependent relaxations to certain agonists in porcine coronary arteries. J Physiol Lond 408: 549-560, 1989.

LI Y, ANAND-SRIVASTAVA MB: Inactivation of enhanced expression of $\mathrm{G}_{\mathrm{i}}$ proteins by pertussis toxin attenuates the development of high blood pressure in spontaneously hypertensive rats. Circ Res 91: 247-254, 2002.

PINTÉROVÁ M, KUNEŠ J, DOBEŠOVÁ, ZICHA J: The role of $\mathrm{Ca}^{2+}$ influx and $\mathrm{G}_{i}$ proteins in $\alpha_{1}$ - and $\alpha_{2}$-adrenergic vasoconstriction elicited in SHR and WKY rats. Hypertension 48: 769, 2006.

PINTÉROVÁ M, KUNEŠ J, DOBEŠOVÁ, ZICHA J: Calcium influx and alpha-adrenergic vasoconstriction in SHR and WKY rats: the role of voltage-dependent calcium channels and inhibitory G proteins. $J$ Hypertens $\mathbf{2 5}$ (Suppl 2): S22-S23, 2007.

SPITZBARTH-RÉGRINY E, PETITCOLIN MA, BUEB JL, TSCHIRHART EJ, ATKINSONN J, CAPDEVILLEATKINSON C: Pertussis toxin-sensitive $\mathrm{G}_{\mathrm{i}}$-proteins and intracellular calcium sensitivity of vasoconstriction in the intact rat tail artery. Br J Pharmacol 131: 1337-1344, 2000. 